out of truth, rather than to the weight or inertia of the rods themselves.

He further takes this opportunity to state, that in a properly proportioned engine of any assumed horse-power, the only method of diminishing the weight of the moving parts, is to increase the number of strokes-lengthening the stroke will not do it.

December 7 th, 1878.

\title{
ON THE TRANSMISSION OF POWER BY MEANS OF ELECTRICITY.
}

\section{By Profs. Elihu Thomson and Edwin J. Houstox.}

The statements recently made as to the size and cost of the cable that would be needed to convey the power of Niagara Falls to a distance of several hundred miles by electricity, have induced the authors to write the present paper, in the hope that it may throw light upon this interesting subject.

As an example of some of the statements alluded to, we may cite the following, viz.: That made by a certain electrician, who asserts that the thickness of the cable required to convey the current that could be produced by the power of Niagara, would require more copper than exists in the enormous deposits in the region of Lake

FIG. 1 .

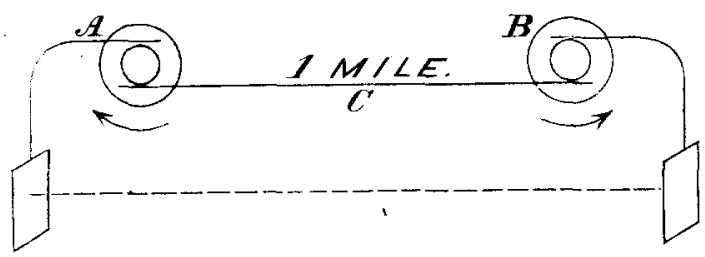

Superior. Another statement estimates the cost of the cable at about $\$ 60$ per lineal foot.

As a matter of fact, however, thethickness of the cable required to convey such power is of no particular moment. Indeed, it is possible, should it be deemed desirable, to convey the total power of Niagara, a distance of 500 miles or more, by a copper cable not exceeding one-half of an inch in thickness. This, however, is an extreme case, and the exigencies of practical working would not require such restrictions as to size.

The following considerations will elucidate this matter. Suppose two machines connected by a cable, of say 1 mile in length. One of these machines, as, for example, $A$, Fig. 1 , is producing current by 
the expenditure of power; the other machine, $B$, used as an electrical motor, is producing power, by the current transmitted to it from $A$, by the cable $C$. The other terminals, $x$ and $y$, are either put to earth, or connected by a separate conductor.

Let us suppose that the electromotive force of the current which flows is unity. Since by the revolution of $B$, a counter-electromotive force is produced to that of $A$, the electromotive force of the current that flows is manifestly the difference of the two. Let the resistance of $A$ and $B$ together, be equal to unity, and that of the mile of cable and connections between them, the $\cdot 01$ of this unit. Then the current which flows will be $C=\frac{E}{R}=\frac{1}{1 \cdot 01}$. If now an additional machine, $A^{\prime}$, Fig. 2, and an additional motor, $B^{\prime}$, and an additional mile of cable, be introduced into the above circuit, the electromotive

Fig. 2.

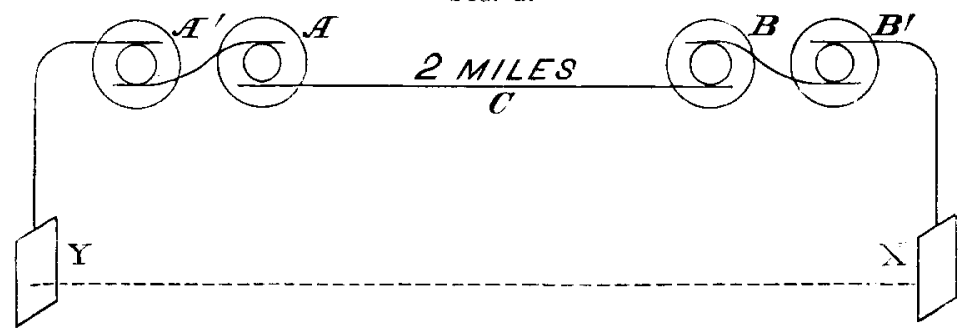

force will be doubled, and the resistances will be doubled, the current strength remaining the same as $C=\frac{E}{R}=\frac{1+1}{1 \cdot 01+1 \cdot 01}=\frac{2}{2 \cdot 02}$. Here it will be seen that the introduction of the two additional machines, $A^{\prime} B^{\prime}$, has permitted the length of the cable $c$ to be doubled, without increasing the strength of the current which flows, and yet allowing the expenditure of double the power at $A A^{\prime}$, and a double recovery at $B B^{\prime}$ of power, or, in other words, a double transmission of power, without increase of current. Increase, now, the number of machines at $A$ to say one thousand, and of those at $B$ in like proportion, and the distance between them, or the length of the cable, one thousand, or in the case we have supposed, make it one thousand miles, its diameter remaining the same. Then although the same current will flow, yet we have a thousand times the expenditure of power at one end of the cable, and a thousand-fold recovery at the 
other end, without increase of current. And the same would be true for any other proportion.

Since the electromotive force is increased in proportion to the increase of power transmission, the insulation of the cable and machines would require to be proportionally increased.

As an example, it may be mentioned that a dynamo-electric machine used for the purpose of $A$ in the figure, may have a resistance of say $40 \mathrm{ohms}$, and produce an electromotive force of say 400 volts. Such a machine might require from three to five horse-power when used in connection with a suitable motor $B$, for recovery of the power transmitted.

If the resistance of the motor $B$, be say $60 \mathrm{ohms}$, and the cable transmitting the currents a distance of one mile, be one ohm, then the current $C=\frac{400}{60+40+1}=\frac{400}{101}$. If now, one thousand machines and one thousand motors, and a thousand miles of cable, each of the same relative resistances be used, the current $C=\frac{1000 \times 400}{1000 \times 101}$, which has manifestly the same value as before. If our supposition of the power used to drive one machine be correct, then from three to five thousand horse-power would be expended in driving the machines, and possibly about fifty per cent. of this amount recovered. Then we have from 1500 to 2000 horse-power conveyed a distance of 1000 miles. What diameter of copper cable will be required for such transmission? Since this cable is supposed to have the resistance of one ohm to the mile, calculation would place the requisite thickness at about $\frac{1}{4}$ inch. If, however, the distance be only 500 miles, then the resistance per mile may be doubled, or the section of the cable be decreased one-half, or its diameter will be less than the $\frac{1}{5}$ inch.

For the consumption of 1,000,000 horse-power, a cable of about 3 inches in diameter would suffice under the same conditions. However, by producing a much higher electromotive force, the section of the cable could be proportionally reduced, until the theoretical estimates, which we have given in the first part of this paper, might be fulfilled. The enormous electromotive force required in the above calculation, would, however, necessitate such perfect insulation of the cable, that the practical limits might soon be reached. The amount of power required to be conveyed in any one direction, would, of course, be dependent upon the uses that could be found for it; and it is hardly 
conceivable that any one locality could advantageously use the enormous supposed power we have referred to.

Stripped of its theoretical considerations, the important fact still remains, that with a cable of very limited size, an enormous quantity of power may be transferred to considerable distances. The burning of coal in the mines, and the conveyance of the power generated by the flow of rivers, may therefore be regarded as practicable, always, -however, remembering that a loss of about 50 per cent. will be almost unavoidable.

It may be mentioned that Dr. C. W. Siemens, and Sir William Thomson, have recently made statements that are in general accordance with the views here expressed.

\section{A CURIOUS THERMO-MAGNETIC MOTOR.}

\section{By Profs. Edwix J. Houston and Elihu Thomson.}

During investigations by the authors, concerning the increase in the coercitive force of steel by changes of temperature, the following curious thermo-magnetic motor was devised. This motor, though devoid of practical value, will, no doubt, be of sufficient scientific interest to warrant a short description.

In the figure, a disc or ring of thin steel, $D$, is mounted on an axis, so as to be quite free to move. The edges of the wheel are placed opposite the poles $H$ and $S^{\prime}$, of a magnet. In this position the wheel of course becomes magnetized by induction.

If now, any section of the wheel, as $H$, be sufficiently heated, the disc will move in the direction shown by the arrow. The cause of this motion is as follows: The section $H$, when

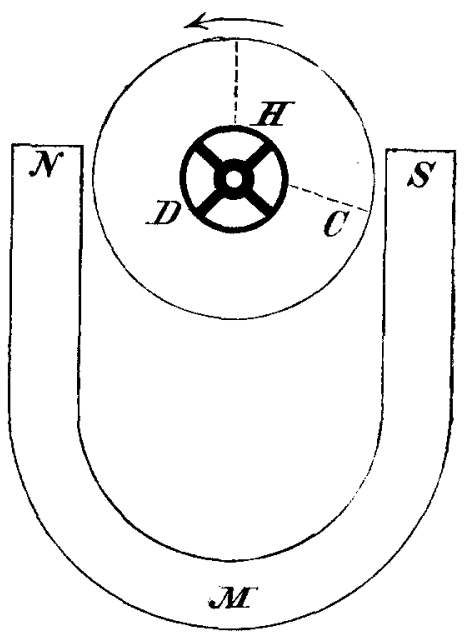
heated, has its coercitive force thereby increased, and being less powerfully magnetized by the induction of the pole $S$, than the portion $C$, immediately adjacent to it, the attraction exerted by the pole $S$ 